\title{
Cathartic narratives for chaotic thinking
}

\author{
CMAJ Podcasts: article reading at https://soundcloud.com/cmajpodcasts/160831-enc
}

$\Gamma$ wo years with severe, chronic lower back pain feels like an eternity, yet people in my pain support group have endured pain for decades. They talk about their losses: employment, education, socializing, marriages, relationships, powerful emotions, spirituality, homes, recreation and freedom to travel. They talk about their frustration with a medical system that mostly fails them. Some openly discuss the possibility of suicide if their suffering becomes unbearable.

Pain meant that I went from being an active person with meetings to attend, students to teach and projects to run to being a person whose life became penciled in - tentative. Lower back pain with persistent pain radiating to my lower leg and foot made me feel as though my foot was a wooden plank attached by a floppy hinge. When I walked, I could hear the step of one foot and the slap of the wooden foot. My loss of mobility was devastating. Getting up and out of the house became a monumental task, and I could no longer drive. Travelling to and from work, I found the crowded buses caused intense anxiety. I feared being jostled or someone stepping on my foot, which would cause excruciating pain. With unsure balance, I feared falling or crashing into others.

I fall now - a lot. I fall because of uneven sidewalks, not feeling a stair, or sometimes for no reason at all. I never know when it will happen, which makes me anxious. And falling in public has the added humiliation of well-meaning people helping you: "Are you okay sir?" I answer politely: "Yes, thank you." But I want to say, "No, I am not fucking okay." Bruised hips, shoulders and knees punctuate my already-pained body.

During the first year, three to four hours of sleep a day was good. I felt like I was 100 years old. I learned

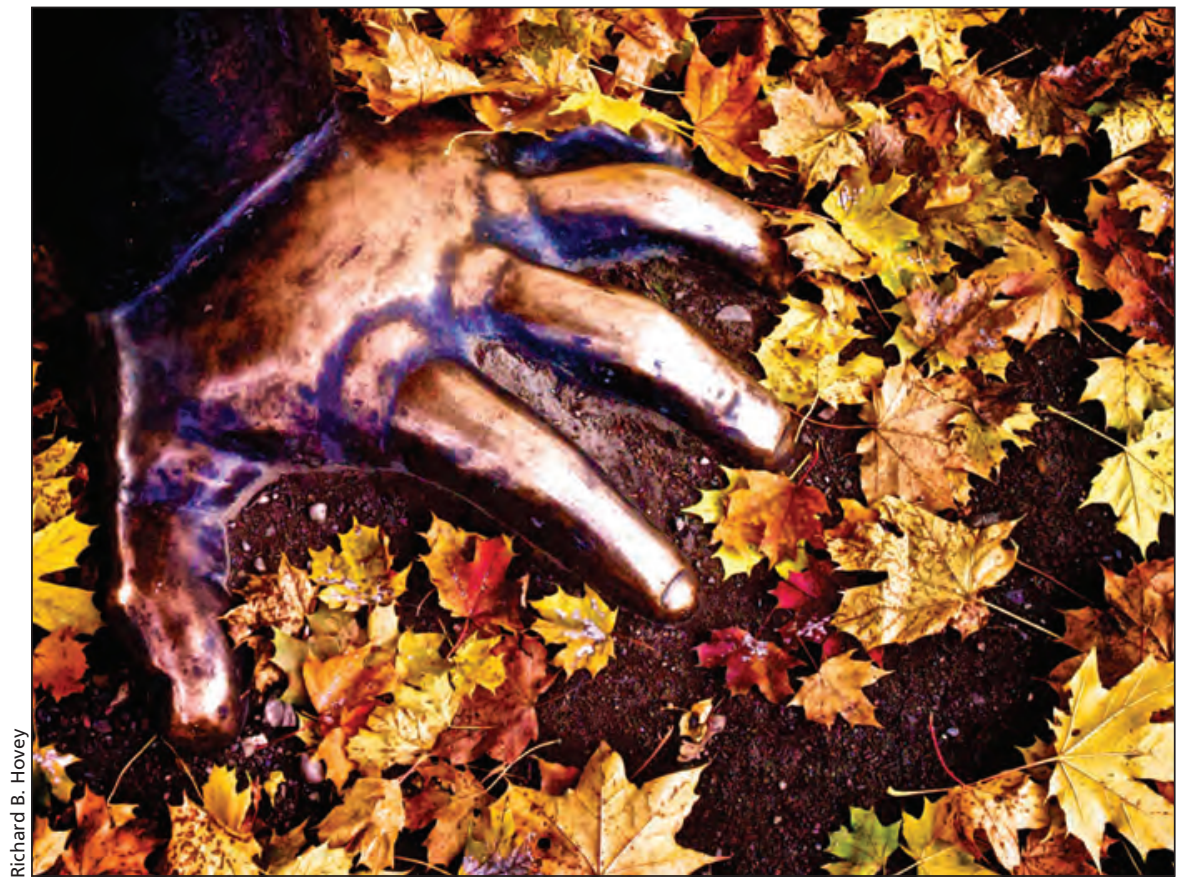

about a whole new level of exhaustion, where it felt like every single cell in my body had failed me. Being awake in the middle of the night in pain meant hours with ice packs and heating pads. Pain killers became part of my life. I became increasingly irritable and frustrated.

Pain also caused me to withdraw from the world. Social events with friends, work and recreation became impossible because even if I did attend, the thought of party talk seemed so inconsequential and trivial. Talking about pain with people not in pain was in itself painful: their eyes glazed over - they wanted to escape. I didn't blame them. And so it became better for everyone if I simply faded away and hid. I grew isolated.

Chronic pain is exhausting, relentless and life shattering. I cannot think outside the oppression of pain. I have foggy concentration, chaotic thoughts, fear and anxiety. Pain not only has changed what and how I see, hear, smell and touch - in short how I engage with the world - but it also has changed the way I interpret the world as I struggle to make sense of a radically different life.

Writing is now an agonizing chore; my words suffer with me as I try to put coherent thoughts on paper. When I sit for only a few minutes, pain shoots down my leg into my foot. I stand and I feel several different kinds of pain simultaneously. There is no in-between time where I can find peace of mind, to think, to write research grants, to prepare courses to teach, to attend meetings.

I attend support groups for people living with pain, where many reveal that they have discovered their pain can be lived with, only differently. Often when I talk about pain, people hear it as complaining. People turn away. People who are not in pain grow tired of people who live with pain and their cloudy, 
depressive narratives. But the pain narrative is rightfully chaotic, and it needs a safe place to be spoken. This is an important role of pain support networks. Not only do they help people speak of their life with pain, they help others who listen, reflect and interpret these narratives into a meaning for their own lives. For some, the support group provides a chance to transform chaotic thoughts into cathartic narratives.

I find writing serves a similar function. Although the act of writing has become onerous, it helps me make sense of my inner chaotic thinking and cathartically to bring my struggle for hope into the world. It appears that an important aspect of learning to live with chronic pain involves expressing our thoughts in narrative, whether written or visual. In this way, we can confront what pain means to us.

Learning to live with pain also involves a capacity to re-tell your story: to re-story. This new narrative presents a possible way to see beyond my suffering, a way to let go of my previous identity, which has become imbued in loss, and imagine possibilities for engaging in the world again. The new narrative begins with surrendering to the situation, not giving up, but acknowledging that chronic illness means the pain will last a long time.

When my words fail, I turn to the text of others to help me reconcile my evolving life with pain. Through hermeneutics, the theory and methodology of interpretation, I learn to make sense of my previously chaotic unexaminable pained life. ${ }^{1}$ Reflective interpretive practice, and the attendant deep introspection, have given me a way to purposefully review my life situation, a means to articulate my thoughts and emotions. Hermeneutics "deciphers the obscure, both pursues sense and projects meaning, reveals the hidden, contests what is given, discerns the possible and re-animates whatever the present has silenced." ${ }^{2}$ Reflective interpretive practice helps me to acknowledge and understand that there is life after pain, but I find I have to actively seek it out, challenge unhelpful thinking and confront hopelessness. This is such a relief for a person living in chronic pain. It liberates one from the scientific tyranny of medical pathologic narratives and opens up a means to live more - or again — as a person with a place in the world.

Although bright lights and colours continue to be painful, sharp noises make me twitch and cringe, crowds produce anxiety, concentration diminishes, and pain still can feel numb, shooting, burning and stinging all at the same time, I have found, through the words of the philosopher Richard Kearney, that "narrative imagination - in the guise of historical or literary testimony - may help prevent past traumas from becoming fixed in pathological forms of melancholy, amnesia or repetition." ${ }^{3} \mathrm{We}$ become emancipated from our repetitive traumatic narratives, cathartically.

I realized my own transformation into this new narrative when I was asked how I was feeling recently and, rather than defaulting to my suffering narrative, I said, "I feel well, thank you." And I meant it. I seemingly began my re-storying of my life with pain.
Reflection, interpretation, imagination and conversation through support groups, visual arts, philosophy, music, dimmer switches, poetry and literature, all helped me cathartically to begin to re-story my pained life. Once the medical melodrama fades away, we become the Other to whom we once believed we were. As Kearney writes, "some sufferers of blocked or melancholic memory have, first, to become very bad storytellers - making their lives basically unreadable - if they are ever to begin to retell their lives again." $4 \mathrm{My}$ level of pain has plateaued to a level where pain does not rule my world as much. I am fortunate. I have learned to embrace ambiguity as part of an unfolding story, not one confined merely by my pained body, but as an ongoing and evolving lifelong endeavour.

\section{Richard B. Hovey MA PhD}

McGill University, Montréal, Que.

\section{References}

1. Ricoeur P. Hermeneutics and the human sciences: essays on language, actions and interpretation. Thompson JB, translator. Cambridge (UK): Cambridge University Press; 1998.

2. Mission statement. Dundee (Scotland): The Hermeneutic Exchange. Available: https://sites.dundee. ac.uk/hermeneuticexchange/mission-statement (accessed 2016 Oct. 26).

3. Kearney R. Strangers, gods and monsters. New York: Rutledge Publishing; 2003:182.

4. Kearney R. Strangers, gods and monsters. New York: Rutledge Publishing; 2003:179.

This article has been peer reviewed.

CMAJ 2016. DOI:10.1503/cmaj.160831

"Humanities are the hormones of medicine." - William Osler 